\title{
The care experiences of patients who die in residential hospice: A qualitative analysis of the last three months of life from the views of bereaved caregivers
}

DARYL BAINBRIDGE, PH.D., ${ }^{1}$ MOHANNA GIRUPARAJAH, M.Sc., ${ }^{2}$ HANYAN ZOU, M.Sc., ${ }^{2}$ AND HSIEN SEOW, PH.D. ${ }^{1}$

${ }^{1}$ Department of Oncology, McMaster University, Ontario, Hamilton, Canada

${ }^{2}$ Faculty of Health Sciences, McMaster University, Ontario, Hamilton, Canada

(RECEIVED March 16, 2017; ACCEPTEd May 24, 2017)

\begin{abstract}
Objective: Despite the increasing prominence of residential hospices as a place of death and that, in many regards, this specialized care represents a gold standard, little is known about the care experience in this setting. Using qualitative survey data, we examined the positive and negative perceptions of care in hospices and in other prior settings.

Method: Qualitative comments were extracted from the CaregiverVoice survey completed by bereaved caregivers of decedents who had died in 16 residential hospices in Ontario, Canada. On this survey, caregivers reported what was good and bad about the services provided during the last three months of life as separate open-text questions. A constant-comparison method was employed to derive themes from the responses.

Results: A total of 550 caregivers completed the survey, 94\% (517) of whom commented on either something good (84\%) and/or bad (49\%) about the care experience. In addition to residential hospice, the majority of patients represented also received palliative care in the home (69\%) or hospital (59\%). Overall, most positive statements were about care in hospice $(71 \%)$, whereas the negative statements tended to refer to other settings $(81 \%)$. The hospice experience was found to exemplify care that was compassionate and holistic, in a comforting environment, offered by providers who were personable, dedicated, and informative. These humanistic qualities of care and the extent of support were generally seen to be lacking from the other settings.

Significance of results: Our examination of the good and bad aspects of palliative care received is unique in qualitatively exploring palliative care experiences across multiple settings, and specifically that in hospices. Investigation of these perspectives affirmed the elements of care that dying patients and their family caregivers most value and that the hospices were largely effective at addressing. These findings highlight the need for reinforcing these qualities in other end-of-life settings to create comforting and supportive environments.
\end{abstract}

KEYWORDS: Palliative care, Quality, Inpatient hospice, Hospital, Homecare

Address correspondence and reprint requests to: Daryl Bainbridge, Juravinski Cancer Centre, 699 Concession Street, Room 4-214, Hamilton, Ontario L8 V 5C2, Canada, E-mail: bainbridgd@hhsc.ca.

\section{INTRODUCTION}

Residential hospices-commonly referred to as "hospices" in the United Kingdom, Canada, and other countries-are free-standing inpatient facilities dedicated to providing comprehensive palliative care (Candy et al., 2011; Seow et al., 2013; Sleeman 
et al., 2016). Unlike home-based hospice palliative care, residential hospices are institutional, though they typically emulate a home-like setting. Commonly, hospices are small in size, with under 20 beds, yet spacious with private rooms and large common areas, so as to afford privacy to patients and family members. Care in these facilities has a clear end-of-life intent, including around-the-clock access to providers with palliative care expertise-usually an interdisciplinary team consisting of nurses, physicians, counselors, personal support workers, and volunteers. Patients in residential hospice often face imminent death and generally require a greater intensity of palliative care than can be effectively provided at home or even in hospital (Seow et al., 2017; Ventura et al., 2014; Virdun et al., 2015).

While most individuals prefer to die at home (Gomes et al., 2013), this is not always a feasible option due of the complexity of care and the unavailability of services required to keep the patient comfortable and safe. Even with the expansion and advancement of community-based palliative care services (Teno et al., 2015; Williams et al., 2010; Woitha et al., 2016), enabling a home death still relies heavily on informal support provided by family caregivers, which is not always available or sufficient (Higginson et al., 2013; Morris et al., 2015; Yu et al., 2015). Moreover, compared to hospitals, residential hospices typically offer more appropriate and cost-efficient care to support dying patients. For instance, the daily cost of residential hospice is $\sim \$ 500$ per patient, which is only half to a quarter of hospital care in both publically funded healthcare systems, such as in Canada, and privately funded ones, such as that in the United States (US) (Auditor General of Ontario, 2017; Bekelman et al., 2016; Georghiou \& Bardsley, 2014; Kaiser Family Foundation, 2017).

As of 2015 , there were 26 inpatient hospices in Ontario, most with 8 to 10 beds (212 total) (Residential Hospice Working Group [RHWG], 2015). Provincial regulations govern facility design and provision of care, which are provided at no cost to patients. Nearly all of these hospices receive government funding to cover residential frontline nursing costs; however, capital investment and operational costs are funded through charitable donations (RHWG, 2015; Sussman et al., 2011). The average length of stay in hospice is 19 days. In Ontario, $4 \%$ of all deaths occur in hospice, and similar proportions are reported in the US (4\%) and England (6\%). The percentage of residential hospice-based deaths in these countries has increased in recent years (National Hospice and Palliative Care Organization (NHPCO), 2015; RHWG, 2015; Sleeman et al., 2016).

Despite hospices representing an important setting for end-of-life care, and to some extent a gold standard, there has been little research on the care experience of patients in these facilities, particularly in comparison to the other settings of care accessed. The quality of end-of-life care received in settings such as hospices is critical, considering that the majority of patients who die receive palliative care for less than two months (Bennett et al., 2016; NHPCO, 2015; Tanuseputro et al., 2016). Furthermore, it is common for patients to access palliative care from multiple settings and providers (Lawson et al., 2006; Walker et al., 2011), and to transition between care settings during the last weeks of life (Hanratty et al., 2014). To date, research examining the quality of care at the end of life from the patient and family perspectives has largely consisted of quantitative measures of satisfaction, either only including the setting of death or not differentiating between hospice and other care settings. As a result, little is known about the hospice experience and of that relative to palliative care received at home and in hospital. Examination of these perspectives can reveal the most essential tenets of quality palliative care to patients and their family caregivers, and is key to informing improvement of palliative care services.

The objective of the present study was to capture end-of-life care experiences across a wide range of palliative care settings used by deceased patients from the perspective of bereaved caregivers. Focusing on responses from caregivers of patients who died in hospice, we report on the qualitative analysis of open-ended questions as to what was good and bad about care during the last three months of life. These findings will advance our understanding of the relative strengths and weakness of key care settings for dying patients and their families, as well as illuminate important considerations in providing quality palliative care.

\section{METHODS}

\section{Study Design and Population}

Bereaved caregivers of decedents who died in one of 16 participating residential hospices in Ontario completed a questionnaire as part of a survey to capture the patient/caregiver experience at the end of life retrospectively after the patient had died. The instrument, the CaregiverVoice Survey, has been described in detail (Seow et al., 2016). Data collection occurred between January and October of 2015. One inclusion criterion for survey participation was the ability of the caregiver to read and write English. The study received approval from the Hamilton Health Sciences/McMaster University research ethics review board (Hamilton, Ontario). 
Table 2. Settings of care used and commented upon $(N=550)$

\begin{tabular}{lccc}
\hline \hline Setting/provider of care & $\begin{array}{c}\text { Used anytime in last } \\
3 \text { months of life, } n(\%)\end{array}$ & $\begin{array}{c}\text { Specified "good" } \\
\text { comment, } n(\%) * *\end{array}$ & $\begin{array}{c}\text { Specified "bad" } \\
\text { comment, } n(\%) * *\end{array}$ \\
\hline Residential hospice & $550(100.0)$ & $383(69.6)$ & $65(11.8)$ \\
Homecare & $379(68.9)$ & $149(39.3)$ & $100(26.4)$ \\
Stayed in hospital & $306(59.4)$ & $51(16.7)$ & $85(27.8)$ \\
Palliative care doctor & $246(46.2)$ & $38(15.4)$ & $6(2.4)$ \\
Cancer center & $225(43.4)$ & $14(6.2)$ & $9(4.0)$ \\
Long-term care home & $61(11.9)$ & $1(1.6)$ & $6(9.8)$
\end{tabular}

* Reported by caregiver; multiple settings are possible.

** Percentage of patients who used that setting.

care at a cancer center (Table 2). The majority (75\%) of patients were in hospice for less than a month before death, with $31 \%$ staying for a week or less.

Among caregiver respondents, some 84\% (464) reported positive comments about care, $49 \%$ (268) reported negative comments, and 6\% (35) completed the survey but provided no open-text comments. The average lengths of good and bad comments were 55 and 92 words, respectively. From these statements, 55 good themes and 45 bad themes emerged and were categorized by the care setting mentioned. Table 2 presents the percentage of caregivers that had a good or bad comment about a specified care setting. Overall, the majority $(71 \%)$ of care-setting-specified positive statements were about care in the hospice. Most of the negative statements (87\%) were about other settings of care used during the last three months of life.

\section{What Was Good and Bad about Hospice Care}

Some $70 \%$ of caregivers made a positive comment about hospice care, and $12 \%$ made a negative comment. Table 3 presents the 21 good and 6 bad themes that emerged about hospice care. Caregivers often used general statements such as "outstanding in every way," "beyond anything we could have asked for," and "everything was good" to indicate that the hospice afforded a positive overall experience. Some caregivers specified professionals or individuals in relation to these general comments. The most common good themes were related to the compassion shown by providers, the physical environment in the hospice, and the holistic manner in which the needs of patients and caregivers were met. The singular most prominent bad theme was that the caregivers felt that admission to hospice had occurred too late.

Many (26\%) of the caregivers commented on the great extent to which hospice providers showed compassion, empathy, and support for patient and family:
First, the level of compassion and care given to him to the point that he felt safe and comfortable to pass away at hospice instead of home. Second, the friendly support given to the caregiver and family was welcomed overwhelmingly, giving us a chance to focus just on our time together with him, and giving him the peace of mind. The type of compassionate care that the staff give at hospice is not given at a hospital.

$$
\text { — wife caregiver }
$$

My father's care was caring and very empathetic from ALL homecare, PSW [personal support worker], and hospice workers throughout his illness. - daughter caregiver

A prominent theme was the pleasantness of the hospices' physical environment, with this space being perceived as peaceful, comforting, and allowing adequate privacy for patients and their families:

Good staff and upbeat surroundings-setting and design of hospice [provides a] home-like atmosphere.

$$
\text { — son caregiver (of mother) }
$$

A number of favorable comments and resulting themes related to the hospices' management of patients' pain and symptoms, provision of emotional support, and meeting of personal/practical needs. The care was considered holistic, and the patient and family were treated as one unit:

My husband had excellent care at [name of hospice]. If he couldn't eat the food, they supplied something different, always helped with bathing, daily chores-given openly and with love. Never did he receive a "just a minute." The nurses were always THERE.

— wife caregiver 
Table 3. Unique good and bad themes about hospice care $(N=550)$

$n(\%)$

Hospice good themes

Generally good hospice care unspecified provider

$348(63.3)$

Generally good hospice care by nurses

65 (11.8)

Generally good hospice care by PSWs

$32(5.8)$

Generally good hospice care by physicians

$30(5.5)$

Compassionate, caring, supportive, and/or empathic hospice providers

$145(26.4)$

Pleasant hospice setting (incl. private, peaceful, homelike)

$103(18.7)$

Helpful hospice volunteers

$63(11.5)$

Respectful care at hospice

$62(11.3)$

Good pain and/or symptom management in hospice

$48(8.7)$

Accommodating to guest visits

$39(7.1)$

Hospice providers took time to provide care (including attentive)

$29(5.3)$

Good emotional support

$26(4.7)$

Providers available and willing to answer questions

$20(3.6)$

Personal care needs well met

$15(2.7)$

$14(2.6)$

Responsive hospice care

$14(2.6)$

(including going out of their way to help)

$14(2.6)$

Good spiritual support

$13(2.4)$

Pleasant and/or personable hospice providers

$12(2.2)$

$9(1.6)$

Consistent skill and expertise of hospice providers

$6(1.1)$

Hospice bad themes

Earlier access and/or transfer to hospice

Hospice provider was insensitive, lacked empathy, unpleasant, or lacked respect

$33(6.0)$

$6(1.1)$

Need information and/or reminders about services in hospice

$6(1.1)$

Need more staff and/or services to support patient in hospice

$6(1.1)$

Inadequate pain and/or symptom management in hospice

$5(0.9)$

Volunteers in hospice need more training

$5(0.9)$

The hospice and all the staff and volunteers could not have been more kind to my husband and our family, offering emotional support and explaining the stages of his death and reassuring us that he was not suffering. Meals and beds [were] provided for [the] family to be able to stay with my husband.

— wife caregiver

Finally, the benevolent nature of the care provided by the hospice was perceived as being respectful, dedicated, informative, and personable and portrayed across various themes:

He was at the [name of hospice] for eight days. Those were the best days for him and for his family. The staff was so caring. They treated him [with] dignity and respect and helped him when he was in pain. They didn't ignore him like they did in the hospital, or like homecare did. Hospice staff were also supportive of the caregiver-me. Never had that kind of support in the last seven years that I had been caring for dad as his health declined.

— daughter caregiver
Caregivers expressed few negative sentiments about the hospice experience. The primary complaint (6\% of caregivers) was that admission to hospice should have happened earlier. In some cases the patient died within 1 to 2 days of transfer, and caregivers wished that the patient had had more time to adapt to the move or to benefit from the services offered before death. Some caregivers recognized the limited number of hospice beds and felt fortunate that their loved one was placed in this setting:

[I recommend] earlier entry criteria for the hospice. By the time she was transferred to the hospice, her disease had progressed so quickly that she was totally bedridden and unable to take in the beautiful surroundings.

— daughter caregiver

I pray that when my time comes that I will be fortunate enough to get a bed in hospice. Nothing was bad about the care, but we need more beds and more staff and more hospices. — wife caregiver

The remaining negative themes about hospice include perceptions that certain individual providers 
lacked compassion or competency, that pain and symptom management were inadequate, or that the caregiver would have liked to be better informed about the patient's prognosis or the availability of services:

What was disappointing was the fact that our family tried their best to be with my husband as much as possible, but we were not made aware that he was so close to death. We would have liked to be there, thinking that the personnel in the hospice would have some indication that the situation was deteriorating rapidly.

— wife caregiver

We compared responses between male and female caregivers, which overall were similar in terms of the themes expressed. Some relatively small observed differences were found in perceptions of hospice for the following themes (proportion of women vs. men respondents): respectful care (13 vs. $6 \%$ ); accommodating to guest visits (9 vs. $3 \%$ ); good emotional support ( 6 vs. $2 \%$ ); and providers available and willing to answer questions (5 vs. $1 \%$ ). However, this discrepancy is partially due to the lower proportion of male caregivers ( $-11 \%$ compared to women caregivers) who commented specifically on care in the hospice.

\section{Comparison to Other Settings of Care}

The relative quality of the care settings patients encountered prior to hospice can be ascertained from the magnitude of caregivers' good and bad statements directed at a particular setting, as well as the statements many caregivers provided that directly compared hospice to another setting. For non-hospice settings, the ratio of good comments to bad was more equivalent (Table 4). Overall, although many of the patients wished to die at home, most caregivers $(96 \%)$ indicated in the quantitative data that hospice was the right place of death given the circumstances. Many felt relief in the transfer of the patient to hospice, allowing caregivers to focus on spending quality time with their loved one:

The stay in the hospital prior to entering hospice was unpleasant. For days he lay in an [emergency room] until healthcare providers figured out what to do with him. One day we were told one thing; the next we were told something else. His room was small. There was no place for his spouse or children to sit quietly by his bedside. There was no privacy. He was agitated because of all of this, and so were we. We were confused and stressed. When he entered hospice, this completely changed and brought about relief and peace for him and all the family.

\section{— daughter caregiver}

In retrospect, many caregivers stated that the different aspects of palliative care support that the patient needed at the end of life were largely absent from care settings prior to hospice, particularly in hospital. The most prominent bad themes that emerged for specified settings other than hospice were: "More homecare services were needed" (36 [9.5\%]); "General issues with homecare" (16 [4.2\%]); "General issues with hospital" (56 [18.3\%]); "Hospital provider was insensitive, lacked empathy, unpleasant, or lacked respect" (23 [7.5\%]); and "Needed better communication with hospital providers" (23 [7.5\%]). In particular, the issues with homecare tended to revolve around the need for more support and greater familiarity with providers. In hospital, the more pronounced problems were the demeanor of providers and a lack of a palliative care understanding:

They tried too hard to fix something that couldn't be fixed in the hospital. Earlier decision to go to hospice [needed] - the outcome was clear, and he was kept in pain too long.

— male friend caregiver

Homecare was good, too, but not enough. Homecare personnel are not available when really needed, such as at night. One visit a week from a nurse, and two from a personal support worker are not enough when one is alone with a dying person, especially when the caretaker is older, too.

— wife caregiver

Although the care experience in home, hospital, and long-term care facilities tended to be less favorable than that of hospice, some caregivers expressed satisfaction with all of the care received during the last three months of life, praising the compassion and skill that certain homecare and hospital providers exhibited. Similar to hospice, the most prominent good themes that emerged for other settings specified were: "Generally good homecare" (101 [26.6\%]); "Good specified homecare provider" (108 [28.5\%]); "Compassionate homecare providers" (32 [8.4\%]); "Generally good hospital care" (30 [9.8\%]); and "Good specified hospital provider" (32 [10.5\%]) (denominator $=$ number who accessed the setting):

We received wonderful care from all caregivers; our own doctor [available 24 hours/day], our homecare nurse and case manager, the oncologist and the hospital staff, and others as well. We could not 
Table 4. Unique good and bad themes about home and hospital care

Homecare themes $(n=379)$

\begin{tabular}{|c|c|c|c|}
\hline Good themes & $n(\% *)$ & Bad themes & $n(\%) *$ \\
\hline $\begin{array}{l}\text { Generally good homecare, unspecified } \\
\text { provider }\end{array}$ & $101(26.6)$ & $\begin{array}{l}\text { Needed more staff and/or services to support patient } \\
\text { in home }\end{array}$ & $36(9.5)$ \\
\hline Generally good homecare care by nurses & $71(18.7)$ & Issues with homecare in general & $16(4.2)$ \\
\hline $\begin{array}{l}\text { Generally good homecare care by personal } \\
\text { support workers }\end{array}$ & $37(9.8)$ & $\begin{array}{l}\text { Would like the same homecare providers to come to } \\
\text { the home }\end{array}$ & $15(4.0)$ \\
\hline $\begin{array}{l}\text { Generally good homecare care by } \\
\text { occupational therapists/ } \\
\text { physiotherapists }\end{array}$ & $5(1.3)$ & $\begin{array}{l}\text { Scheduling issues with homecare services and } \\
\text { providers }\end{array}$ & $13(3.4)$ \\
\hline $\begin{array}{l}\text { Compassionate, caring, supportive, and/or } \\
\text { empathic homecare providers } \\
\text { (unspecified) }\end{array}$ & $18(4.7)$ & Getting access to homecare services was difficult & $11(2.9)$ \\
\hline $\begin{array}{l}\text { Compassionate, caring, supportive, and/or } \\
\text { empathic homecare nurses }\end{array}$ & $7(1.8)$ & $\begin{array}{l}\text { Homecare provider(s) lacked training and/or } \\
\text { experience (including questionable practices) }\end{array}$ & $10(2.6)$ \\
\hline $\begin{array}{l}\text { Compassionate, caring, supportive, and/or } \\
\text { empathic homecare personal support } \\
\text { workers }\end{array}$ & $7(1.8)$ & $\begin{array}{l}\text { Homecare needed to be better organized and } \\
\text { coordinated }\end{array}$ & $10(2.6)$ \\
\hline Support enabled patient to remain at home & $14(3.7)$ & $\begin{array}{l}\text { Care and services from unspecified homecare } \\
\text { provider lacking }\end{array}$ & $10(2.6)$ \\
\hline Responsive homecare & $9(2.4)$ & $\begin{array}{l}\text { Homecare case manager was insensitive, lacked } \\
\text { empathy, unpleasant, or lacked respect }\end{array}$ & $9(2.4)$ \\
\hline $\begin{array}{l}\text { Good pain and/or symptom management in } \\
\text { home }\end{array}$ & $9(2.4)$ & $\begin{array}{l}\text { Care and services from personal support worker(s) } \\
\text { lacking }\end{array}$ & $9(2.4)$ \\
\hline $\begin{array}{l}\text { Homecare providers took time to answer } \\
\text { questions and educate patient and family }\end{array}$ & $6(1.6)$ & $\begin{array}{l}\text { Inadequate pain and/or symptom management at } \\
\text { home }\end{array}$ & $6(1.6)$ \\
\hline $\begin{array}{l}\text { Regularity in homecare providers (i.e., the } \\
\text { same providers visit) }\end{array}$ & $6(1.6)$ & $\begin{array}{l}\text { Homecare nurse(s) insensitive, lacked empathy, } \\
\text { unpleasant, or lacked respect }\end{array}$ & $6(1.6)$ \\
\hline Respectful homecare & $6(1.6)$ & $\begin{array}{l}\text { Equipment needed at home was slow to arrive, slow } \\
\text { to be removed, did not come when scheduled, and/ } \\
\text { or did not accompany caregiver education or } \\
\text { assistance }\end{array}$ & $6(1.6)$ \\
\hline \multirow[t]{4}{*}{ Specialized equipment and care at home } & \multirow[t]{4}{*}{$6(1.6)$} & Inconsistent quality and amount of homecare & $6(1.6)$ \\
\hline & & Private homecare costs too high & $6(1.6)$ \\
\hline & & $\begin{array}{l}\text { Homecare providers' communication with family } \\
\text { and patient lacking }\end{array}$ & $5(1.3)$ \\
\hline & & Needed more doctor visits at home & $5(1.3)$ \\
\hline
\end{tabular}

Hospital care themes $(n=306)$

\begin{tabular}{|c|c|c|c|}
\hline Good themes & $n(\% *)$ & Bad themes $(n=306)$ & $n(\%) *$ \\
\hline \multicolumn{4}{|c|}{ Hospital care themes $(n=306)$} \\
\hline Good themes & $n(\% *)$ & Bad themes $(n=306)$ & $n(\%)^{*}$ \\
\hline $\begin{array}{l}\text { Generally good homecare, unspecified } \\
\text { provider }\end{array}$ & $30(9.8)$ & Issues with hospital care in general & $56(18.3)$ \\
\hline $\begin{array}{l}\text { Generally good homecare care by } \\
\text { physicians }\end{array}$ & $16(5.2)$ & $\begin{array}{l}\text { Hospital care provider was insensitive, lacked } \\
\text { empathy, unpleasant, or lacked respect }\end{array}$ & $23(7.5)$ \\
\hline Generally good homecare care by nurses & $16(5.2)$ & $\begin{array}{l}\text { Needed more and better communication with } \\
\text { hospital care providers }\end{array}$ & $23(7.5)$ \\
\hline \multirow[t]{6}{*}{$\begin{array}{l}\text { Compassionate, caring, supportive, and/or } \\
\text { empathic hospital providers }\end{array}$} & $6(2.0)$ & $\begin{array}{l}\text { Needed more staff and/or services to support } \\
\text { patients in hospital }\end{array}$ & $17(5.6)$ \\
\hline & & $\begin{array}{l}\text { Inadequate pain and/or symptom management in } \\
\text { hospital }\end{array}$ & $13(4.2)$ \\
\hline & & More responsive hospital care needed & $13(4.2)$ \\
\hline & & $\begin{array}{l}\text { Inadequate accommodations (including bed) in } \\
\text { hospital }\end{array}$ & $9(2.9)$ \\
\hline & & $\begin{array}{l}\text { More communication and coordination needed } \\
\text { between hospital care providers }\end{array}$ & $9(2.9)$ \\
\hline & & Personal care at hospital was lacking & $5(1.6)$ \\
\hline
\end{tabular}

* The calculated percentages reflect the number of patients who received care in the setting. 
have had better and more supportive care. My husband lived a long while under palliative care, and we had superb care. We were able to establish strong bonds and relationships that gave both my husband and me a feeling of constant support as we walked the journey.

— wife caregiver

\section{DISCUSSION}

Our study examined bereaved caregivers' open-text responses as to what was good and bad about the care their loved one received in residential hospice and other settings of care accessed during the last three months of life. To our knowledge, our study is one of the first to qualitatively explore care experiences across multiple settings, and specifically that in hospices, using a population-based sample. We found that most caregivers offered a positive recounting of the hospice experience, specifying the constituents of quality that can inform improvement in this and other care settings. The majority of patients also received care in the home and in hospital, which were regarded by some as favorable encounters, although for many caregivers the transition to hospice was perceived as an improvement to the prior palliative care support provided.

While the quality of practical support, pain relief, and symptom management were frequently mentioned by caregivers, these aspects of palliative care did not emerge as the most prominent themes from the good (or bad) comments. What the hospices appeared to excel at were the psychosocial elements of care in the delivery of services that were patientand family-centric, compassionate, and respectful, in a physical setting that, in itself, was comforting, peaceful, and fostered privacy. The importance of the manner in which care is delivered, as opposed solely to clinical precision, has been emphasized in examinations of what quality palliative care means to patients and specialized healthcare providers (Hales et al., 2008; Heyland et al., 2006; Mistry et al., 2015). Although some caregivers felt that homecare and hospital care adequately met the patient's physical needs, caregivers tended to be less likely to exalt the humanistic qualities of this care, compared to that in hospice. Our exploratory analysis of theme prominence by gender found little difference between male and female caregivers.

Large-scale surveys-including the National Survey of Bereaved People (VOICES) in England and the Family Evaluation of Hospice Care (FEHC) survey in the US-have examined satisfaction with multi-setting care at the end of life from the perspective of bereaved caregivers, and have demonstrated divergence in ratings of hospice compared to other settings similar to those in our findings (Connor et al., 2005; Office for National Statistics [ONS], 2015). In the latest VOICES study (ONS, 2015; $n=$ $21,300), 76 \%$ of caregivers rated hospice care as "excellent" (as opposed to "good," "fair," or "poor") compared to $43 \%$ in the home and $41 \%$ in hospital (ONS, 2015). In a prior sample of VOICES respondents $(n=40)$ in which setting differences were explicated, hospice care was regarded as providing better pain control, more sufficient communication, and was more respectful, compared to care provided in hospital (Addington-Hall \& O'Callaghan, 2009). In terms of the FEHC data, care setting comparisons have only been published from one hospice palliative care agency, located in Pennsylvania (2008-2013; $n=1,611$ ) (Ong et al., 2016). Among caregivers of patients who died in an inpatient hospice unit, $88 \%$ rated care as "excellent" (on a 5-point scale) compared to $73 \%$ of those who died in home hospice care. The covariate found to be associated with higher satisfaction in both settings was being informed about the patient's condition, and in the homecare group also having the right amount of support for the patient's anxiety. These studies provide some insights into the qualities of residential hospice that contribute to higher satisfaction; however, the quantitative approaches taken potentially exclude important factors that culminate the care experience and what is actually meaningful to the patient and caregivers. Moreover, the extent to which care setting experiences influence perceptions of subsequent settings remains to be investigated.

Unfortunately, few qualitative studies exist on perceived care at residential hospices that could be compared to our findings. An in-depth study of caregivers $(n=10)$ of patients in a hospice in New Zealand found that these experiences were characterized by staff being attuned to individual patients' needs and preferences in an environment that engenders qualities similar to those found in our study (Bolton et al., 2016). A recent meta-synthesis of the palliative care experience in hospital, based on patient and caregiver narratives from 16 studies, identified 6 essential themes, seemingly applicable to all care settings: expert care, effective communication and shared decision making, respectful and compassionate care, adequate environment for care, family involvement, and financial affairs (Virdun et al., 2016). These authors report that these specified priories have remained consistent over time-also reflecting continuing gaps in this care (Cardona-Morrell et al., 2016; McCourt et al., 2013; Pringle et al., 2015; Robinson et al., 2014). The findings of these studies and ours characterize the optimal type of care that needs to be available to dying patients, regardless of setting, and sets a standard for system development. 
The findings from our study exemplify prior presumptions of residential hospices as being centers of excellence in palliative care (Addington-Hall \& O'Callaghan, 2009; Finlay et al., 2002; Grande et al., 2003). Most caregivers were expressive of the positive effect that the hospice had on death. This is presumable given that these hospices were founded based on a philosophy of personalization, compassion, and comfort, rather than with a curative focus, and are accountable to the local community. The hospices carefully recruit professionals and volunteers with the skill and demeanor to promote the hospice philosophy. Furthermore, great consideration goes into the design of residential hospices to create comforting spaces, rather than medical or institutional ones, which complement the nature of the care provided (Niedzielski et al., 2016; Verderber, 2014). The dilemma is that hospice beds are limited and that placement is a reality for only a small percentage of the general population at the end of life. However, the principles of hospice-namely, the residing philosophy of care, the quality of staff, and the physical environment-are transferable to other care settings, as was evident in positive accounts of select home and hospital care. Particularly in hospital, adopting a hospice approach to care for the dying (e.g., private spaces, specialized providers, patientand family-centric care) has been shown to significantly increase patient and caregiver satisfaction and improve system outcomes (Gade et al., 2008; Higginson \& Evans, 2010; Isenberg et al., 2017).

The present study has inherent limitations in terms of its representativeness and the depth of caregiver perspectives examined, and given that these data are a proxy measure of patients' experiences. The responses elicited are a function of the extent to which patients voiced their options to the caregiver for the care being offered, as well as the caregivers' own expectations, the degree to which they witnessed the care provided, and their ability to recall these encounters. Collecting data from patients who are actively dying is a challenge, as they are often too ill to respond. Research evidence has found bereaved caregivers to be an adequate substitute for collecting these data directly from the patient (Tang \& McCorkle, 2002), and this approach also has the advantage of including care perceptions near death, which is not otherwise possible. Another study limitation is that open-text comments were only obtained from about $40 \%$ of the caregivers surveyed, which may have resulted in biases in opinion (e.g., exaggeration of extreme perspectives). In addition, the survey approach to elicit perceptions most likely lacks the depth possible from personal interviews, as was evident in some caregivers merely stating that the care was good, without further elaboration. Despite these limitations, we were able to obtain rich data from a large number of caregivers with a diversity of perspectives. Additional research is required that explicitly asks patients and caregivers to articulate differences perceived between palliative care settings experienced and explore the relativity of care perceptions based on settings encountered, in order to further inform system quality improvement.

Our examination of the reported experiences across multiple settings during the last months of life affirms the elements of care that patients and their caregivers most value. The hospices where the patients died were largely effective at addressing these priorities, and the other settings to a lesser extent. This finding suggests the need for expansion of care settings of appropriate palliation, including residential hospice, but also patients' homes, long-term care facilities, and even specialized low-intensity hospital units. The positive qualities of the care experiences in hospice that the caregivers expressed in this study can be reinforced in these other settings to create a comforting and supportive environment for the dying patient and their family.

\section{CONFLICTS OF INTEREST}

The authors hereby declare that they have no conflicts of interest to disclose.

\section{ETHICS APPROVAL}

This study was approved by the Hamilton Health Sciences/McMaster University research ethics review board (Ontario).

\section{REFERENCES}

Addington-Hall, J.M. \& O'Callaghan, A.C. (2009). A comparison of the quality of care provided to cancer patients in the UK in the last three months of life in in-patient hospices compared with hospitals, from the perspective of bereaved relatives: Results from a survey using the VOICES questionnaire. Palliative Medicine, 23(3), 190-197.

Auditor General of Ontario (2017). 2014 Annual Report of the Office of the Auditor General of Ontario, Chapter 3.08: Palliative Care. Ottawa: Ministry of Health and Long-Term Care. Available from http://www.auditor.on. ca/en/content/annualreports/arreports/en14/308en14. pdf.

Bekelman, J.E., Halpern, S.D., Blankart, C.R., et al. (2016). Comparison of site of death, health care utilization, and hospital expenditures for patients dying with cancer in 7 developed countries. The Journal of the American Medical Association, 315(3), 272-283.

Bennett, M.I., Ziegler, L., Allsop, M., et al. (2016). What determines duration of palliative care before death for patients with advanced disease? A retrospective cohort study of community and hospital palliative care provision in a large UK city. BMJ Open, 6(12), e012576. 
Bolton, L., Loveard, T. \& Brander, P. (2016). Carer experiences of inpatient hospice care for people with dementia, delirium and related cognitive impairment. International Journal of Palliative Nursing, 22(8), 396-403.

Candy, B., Holman, A., Leurent, B., et al. (2011). Hospice care delivered at home, in nursing homes and in dedicated hospice facilities: A systematic review of quantitative and qualitative evidence. International Journal of Nursing Studies, 48(1), 121-133.

Cardona-Morrell, M., Kim, J., Turner, R.M., et al. (2016). Non-beneficial treatments in hospital at the end of life: A systematic review on extent of the problem. International Journal for Quality in Health Care, 28(4), 456-469.

Connor, S.R., Teno, J., Spence, C., et al. (2005). Family evaluation of hospice care: Results from voluntary submission of data via website. Journal of Pain and Symptom Management, 30(1), 9-17.

Creswell, J. (2013). Qualitative Inquiry and Research Design: Choosing among Five Traditions, 3rd ed. Thousand Oaks, CA: Sage Publications.

Finlay, I.G., Higginson, I.J., Goodwin, D.M., et al. (2002). Palliative care in hospital, hospice, at home: Results from a systematic review. Annals of Oncology, 13(Suppl. 4), 257-264.

Gade, G., Venohr, I., Conner, D., et al. (2008). Impact of an inpatient palliative care team: A randomized control trial. Journal of Palliative Medicine, 11(2), 180-190.

Georghiou, T. \& Bardsley, M. (2014). Exploring the Cost of Care at the End of Life. London: Marie Curie Cancer Care. Available from https://www.mariecurie.org.uk/ globalassets/media/documents/commissioning-ourservices/why-work/our-impact/2014-nuffield-report.pdf

Gomes, B., Calanzani, N., Gysels, M., et al. (2013). Heterogeneity and changes in preferences for dying at home: $\mathrm{A}$ systematic review. BMC Palliative Care, $12,7$.

Grande, G.E., McKerral, A., Addington-Hall, J.M., et al. (2003). Place of death and use of health services in the last year of life. Journal of Palliative Care, 19(4), $263-270$.

Hales, S., Zimmermann, C. \& Rodin, G. (2008). The quality of dying and death. Archives of Internal Medicine, 168(9), 912-918.

Hanratty, B., Lowson, E., Grande, G., et al. (2014). Transitions at the End of Life for Older Adults-Patient, Carer and Professional Perspectives: A Mixed-Methods Study. Health Services and Delivery Research, Vol. 2. London: National Institute for Health Research: Health Services and Delivery Research.

Heyland, D.K., Dodek, P., Rocker, G., et al. (2006). What matters most in end-of-life care: Perceptions of seriously ill patients and their family members. Canadian Medical Association Journal, 174(5), 627-633.

Higginson, I.J. \& Evans, C.J. (2010). What is the evidence that palliative care teams improve outcomes for cancer patients and their families? Cancer Journal, 16(5), $423-435$.

Higginson, I.J., Sarmento, V.P., Calanzani, N., et al. (2013). Dying at home-is it better: A narrative appraisal of the state of the science. Palliative Medicine, 27(10), 918-924.

Isenberg, S.R., Lu, C., McQuade, J., et al. (2017). Impact of a new palliative care program on health system finances: An analysis of the palliative care program inpatient unit and consultations at Johns Hopkins Medical Institutions. Journal of Oncology Practice, 13(5), e421-e430.
Kaiser Family Foundation (2017). Hospital Adjusted Expenses per Inpatient Day by Ownership. Menlo Park, CA: The Henry K. Kaiser Family Foundation. Available from http://kff.org/health-costs/stateindicator/expenses-per-inpatient-day-by-ownership.

Lawson, B., Burge, F.I., Critchley, P., et al. (2006). Factors associated with multiple transitions in care during the end of life following enrollment in a comprehensive palliative care program. BMC Palliative Care, 5(1), 4.

Lincoln, Y. \& Guba, E. (1985). Naturalistic Inquiry. Beverly Hills, CA: Sage Publications.

McCourt, R., James, P.J. \& Glackin, M. (2013). General nurses' experiences of end-of-life care in the acute hospital setting: A literature review. International Journal of Palliative Nursing, 19(10), 510-516.

Mistry, B., Bainbridge, D., Bryant, D., et al. (2015). What matters most for end-of-life care? Perspectives from community-based palliative care providers and administrators. BMJ Open, 5(6), e007492. Available from http://bmjopen.bmj.com/content/5/6/e007492.

Morris, S.M., King, C., Turner, M., et al. (2015). Family carers providing support to a person dying in the home setting: A narrative literature review. Palliative Medicine, 29(6), 487-495.

National Hospice and Palliative Care Organization (NHPCO) (2015). Facts and Figures: Hospice Care in America. Alexandria, VA: National Hospice and Palliative Care Organization. Available from https://www. nhpco.org/sites/default/files/public/Statistics_Research/ 2015_Facts_Figures.pdf.

Niedzielski, O.K., Rodin, G., Emmerson, D., et al. (2016). Exploring sensory experiences and personalization in an inpatient residential hospice setting. The American Journal of Hospice and Palliative Care, 33(7), 684-690.

Office for National Statistics (2015). Statistical Bulletin: National Survey of Bereaved People (VOICES): England, 2015. London: Office for National Statistics. Available from http://www.ons.gov.uk/peoplepopulation andcommunity/healthandsocialcare/healthcaresystem/ bulletins/nationalsurveyofbereavedpeoplevoices/england 2015.

Ong, J., Brennsteiner, A., Chow, E., et al. (2016). Correlates of family satisfaction with hospice care: General inpatient hospice care versus routine home hospice care. Journal of Palliative Medicine, 19(1), 97-100.

Pringle, J., Johnston, B. \& Buchanan, D. (2015). Dignity and patient-centred care for people with palliative care needs in the acute hospital setting: A systematic review. Palliative Medicine, 29(8), 675-694.

Residential Hospice Working Group (RHWG) (2015). Environmental Scan for Strengthening Residential Hospice Care in Ontario. Toronto: Ministry of Health and Long-Term Care. Available from http://www.hpco.ca/wpcontent/uploads/Environmental-Scan-for-StrengtheningResidential-Hospice-Care-in-OntarioFINAL-March16.pdf.

Robinson, J., Gott, M. \& Ingleton, C. (2014). Patient and family experiences of palliative care in hospital: What do we know? An integrative review. Palliative Medicine, 28(1), 18-33.

Seow, H., Bainbridge, D. \& Bryant, D. (2013). Palliative care programs for patients with breast cancer: The benefits of home-based care. Breast Cancer Management, 2(5), 407-416.

Seow, H., Bainbridge, D., Bryant, D., et al. (2016). The CaregiverVoice Survey: A pilot study surveying bereaved caregivers to measure the caregiver and patient 
experience at end of life. Journal of Palliative Medicine, 19(7), 712-719.

Seow, H., Bainbridge, D., Brouwers, M., et al. (2017). Common care practices among effective community-based specialist palliative care teams: A qualitative study. BMJ Supportive \& Palliative Care, pii: bmjspcare-2016-001221. doi: 10.1136/bmjspcare-2016-001221. Epub ahead of print.

Sleeman, K.E., Davies, J.M., Verne, J., et al. (2016). The changing demographics of inpatient hospice death: Population-based cross-sectional study in England, 1993-2012. Palliative Medicine, 30(1), 45-53.

Sussman, J., Seow, H. \& Bainbridge, D. (2011). Hospice Care in Ontario. Hamilton: Supportive Cancer Care Research Unit. Available from http://palliativecare innovation.com/wp-content/uploads/2015/06/SCCRU_ HospiceReport_2011.pdf.

Tang, S.T. \& McCorkle, R. (2002). Use of family proxies in quality of life research for cancer patients at the end of life: A literature review. Cancer Investigation, 20(7-8), 1086-1104.

Tanuseputro, P., Budhwani, S., Bai, Y.Q., et al. (2016). Palliative care delivery across health sectors: A populationlevel observational study. Palliative Medicine, 31(3), 247-257.

Teno, J.M., Freedman, V.A., Kasper, J.D., et al. (2015). Is care for the dying improving in the United States? Journal of Palliative Medicine, 18(8), 662-666.

Ventura, A.D., Burney, S., Brooker, J., et al. (2014). Homebased palliative care: A systematic literature review of the self-reported unmet needs of patients and carers. Palliative Medicine, 28(5), 391-402.
Verderber, S. (2014). Residential hospice environments: Evidence-based architectural and landscape design considerations. Journal of Palliative Care, 30(2), $69-82$.

Virdun, C., Luckett, T., Davidson, P.M., et al. (2015). Dying in the hospital setting: A systematic review of quantitative studies identifying the elements of end-of-life care that patients and their families rank as being most important. Palliative Medicine, 29(9), 774-796.

Virdun, C., Luckett, T., Lorenz, K., et al. (2016). Dying in the hospital setting: A meta-synthesis identifying the elements of end-of-life care that patients and their families describe as being important. Palliative Medicine, pii: 0269216316673547 . Epub ahead of print.

Walker, H., Anderson, M., Farahati, F., et al. (2011). Resource use and costs of end-of-life/palliative care: Ontario adult cancer patients dying during 2002 and 2003. Journal of Palliative Care, 27(2), 79-88.

Williams, A.M., Crooks, V.A., Whitfield, K., et al. (2010). Tracking the evolution of hospice palliative care in Canada: A comparative case study analysis of seven provinces. BMC Health Services Research, 10, 147.

Woitha, K., Carrasco, J.M., Clark, D., et al. (2016). Policy on palliative care in the WHO European region: An overview of progress since the Council of Europe's (2003) Recommendation 24. European Journal of Public Health, 26(2), 230-235.

Yu, M., Guerriere, D.N. \& Coyte, P.C. (2015). Societal costs of home and hospital end-of-life care for palliative care patients in Ontario, Canada. Health \& Social Care in the Community, 23(6), 605-618. 